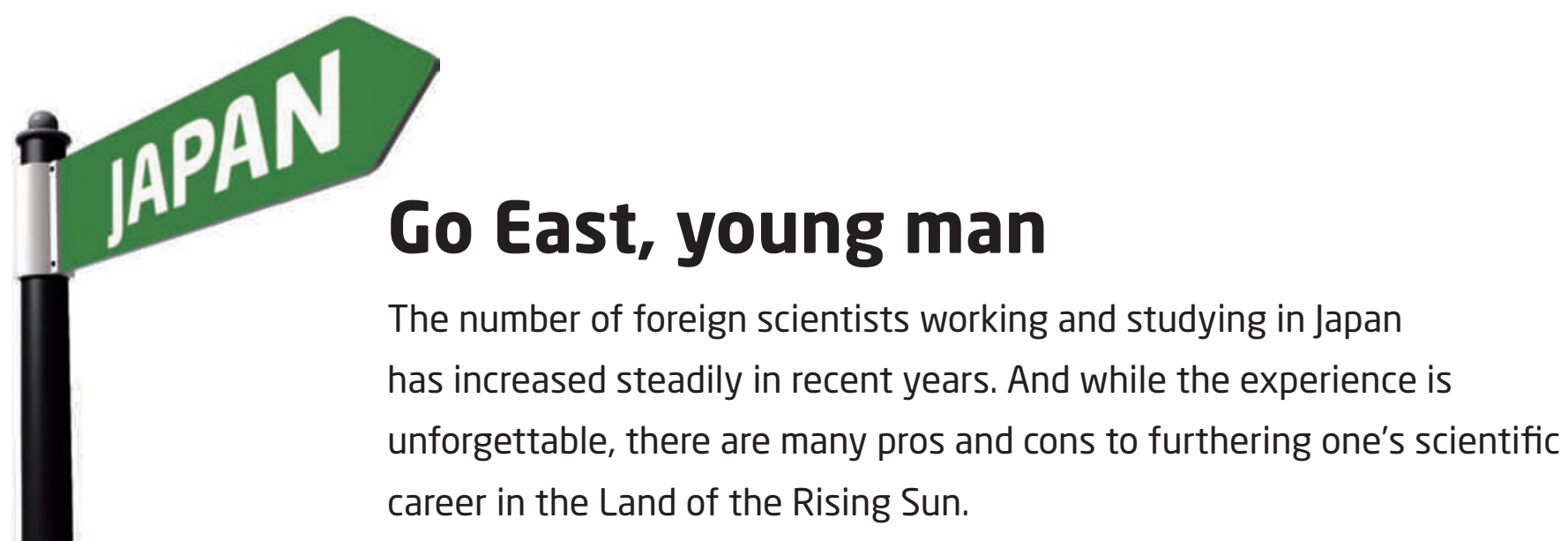

THERE ARE times when the life of a foreign researcher can seem rather more stressed than blessed. Unfamiliar social customs, lack of understanding of local rules and conventions and of course the inevitable language barrier can turn the simplest everyday situations into seemingly insurmountable problems, detracting from the many positive things about living in another country and leaving the expat worker feeling isolated, frustrated and out of their depth. Whilst the above is true of any overseas destination that might be considered for furthering one's career, common wisdom has it that there are few foreign countries as foreign as Japan.

\section{Lost in translation}

Top of the list of obstacles facing foreign researchers in Japan is the problem of communication. Japanese, with its complex grammar, multi-layered respect language and baffling writing system, is universally acknowledged to be one of the most difficult languages for non-native speakers to master. Although the inability to make oneself understood can undoubtedly complicate day-to-day life, for many foreign scientists it causes surprisingly few problems in the lab. "It's not an issue," says Mario Negrello, a postdoctoral researcher from Brazil currently working at the Okinawa Institute of Technology (OIST). "Everything at the OIST is done in English and if I do have a problem I can ask our secretary."

However, according to Cevayir

Coban, a Turkish native who joined the Immunology Frontier Research Centre (IFReC) in Osaka seven years ago to work in the group of world-renowned immunologist Shizuo Akira and who is now an associate professor with her own research team, climbing the academic ladder and becoming independent can bring new pressures. In particular, key tasks such as applying for funding can leave the foreign researcher more dependent on colleagues than would be the case at home. "I need to get grants, and most grant applications are in Japanese, so I have to rely on other people to help me." For this reason, Coban stresses the importance of foreign researchers building a good relationship with an institute's support staff. Despite the pressures of being a foreign researcher, both she and her husband, also an independent research scientist, have never looked back and Coban considers joining the IFReC to be one of her best career moves.

Ashwini Patil, an assistant professor in the Institute of Medical Science at the University of Tokyo (IMSUT), has met with similar language-related obstacles in obtaining funding. Applications for many large public Japanese grants in her field can be submitted in English, yet almost all of the smaller private funds must be applied for in Japanese. Patil, who speaks little Japanese, often feels frustrated knowing that there are a large number of grants out there - some intended specifically to assist female researchers - to which she has no access.

For many expat scientists, however, the lack of Japanese language skills is no barrier to success, especially if they have strong ability in English. For Suzanne Mak from Hong Kong, who is now working at the RIKEN Center for Developmental Biology in Kobe, the fact that she is fluent in English has led to her acting as a de facto liaison officer for her adopted laboratory, an opportunity that might not have arisen at her former institution, the University of Hong Kong. "I speak good English so here I am encouraged to interact closely with visiting professors," she says.

Tom Rodgers, a postdoctoral researcher studying the optical properties of carbon nanotubes at Osaka University, agrees. Whilst conceding that being one of only a limited number of overseas scientists at an institution can sometimes lead to feelings of isolation, he admits that this can have its advantages. "Because there are so few foreigners, people from different fields and with different statuses are willing to work with us. Plus, when a leading researcher is invited to our institute, I am often asked to attend even if I am not the host. I cannot see this happening back home." Negrello has had a similar experience noting that, despite the lack of
"No matter how long you

are in Japan, because

you were not raised

here, you are always

going to feel like an

outsider in some way."

Laurent Safa 


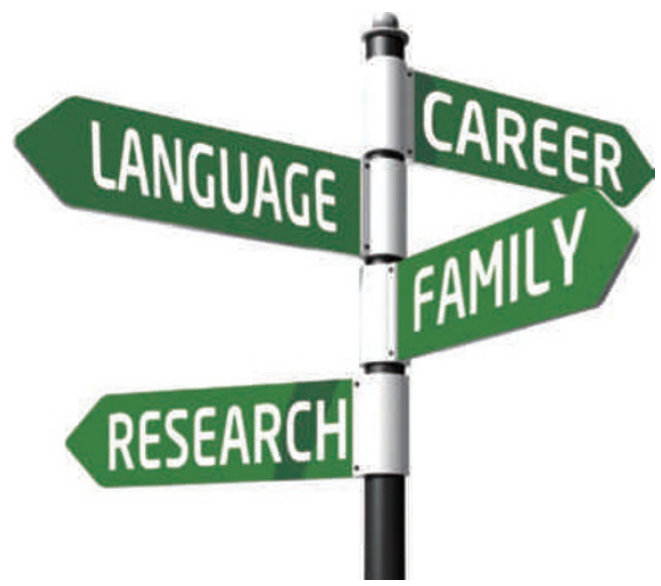

direct flight connections from Okinawa to destinations outside of Southeast Asia, exposure to a large number of internationally renowned visiting scientists is one of the most attractive things about working at the OIST. "I had no idea it would be such a good place to meet people," he says.

\section{Family matters}

Overseas researchers bringing dependants can face additional complications. Few institutions are willing to hire both members of a husband-and-wife research team, but for researchers in longterm relationships, those that do have a substantial advantage over those that do not when considering employment options.

partner finds it hard to adapt to life in Japan, things are no easier as Rodrigo Publio, another Brazilian postdoc at the OIST, testifies. "My wife does not speak the language," he says. "And because Okinawa is small there are few opportunities for her here." Publio cites these difficulties as having contributed to his decision to move on from his current position at the end of his contract.

For researchers with families, the availability of education and childcare can in some cases be another sticking point. Patil, a mother of two, initially struggled to combine parenthood would be such a good place to with high-level medical arearch. Although meet people." her eldest child could participate in an afterschool program, the

Swiss-born string theorist Susanne Reffert was initially attracted to working at the Institute for the Physics and Mathematics of the Universe (IPMU) based at the Kashiwa campus of the University of Tokyo due to its high-quality research and world-class facilities, but the willingness of the IPMU to hire her husband at the same time was a major drawcard and meant that they were able to live together for the first time in years. "Being together is a very important factor for us and one that will influence whether we stay," she says.

Living in any foreign country without the support of a spouse can be difficult, but when a she remarks. "Plus, my kids have a chance to learn a new language."

\section{Read the small print}

Another point of concern for all overseas researchers in Japan is that of conditions of employment, which should, according to Andres Maturana, a tenured assistant professor at the Nagaoka University of Technology (NUT), be established unambiguously in advance. Whilst satisfied with the clear path for his career advancement laid out by the university, something that was lacking at his previous Japanese institution, Maturana got a shock when he actually took up the position. "I didn't know my starting salary until my first day, and frankly it was significantly less than what I had been earning before," he recalls. It was not until later when he was made aware of a series of benefits and bonuses to which he was entitled on top of his basic salary that his fears were allayed. Although now satisfied with his remuneration, Maturana - a ten-year veteran of life in Japan and with good command of the language - feels that the communication of his terms of employment could have been clearer.

The Japanese national pension scheme is another area that Maturana flags as a potential drawback for foreigners working in Japan, whether short- or long-term. Media coverage of the subject and anecdotal evidence from friends and colleagues has left him with doubts about the future viability of the scheme and he is unclear as to the benefits. "Sometimes I feel that on this issue I might be better off in Switzerland," he says. Rodgers in Osaka is equally concerned, but more because he does not expect to stay in Japan long enough to receive the pension for which he is now paying. He is frustrated that as a result of Japan holding only a small number of bilateral pension agreements he will not receive credit for pension premiums paid while working here. This point, in addition to the fact that foreigners who opt out of the national pension program can only recoup three years' worth of contributions regardless of the length of time they have been paying in, acts as a disincentive to remaining in Japan for more than the three-year limit, after which pension payments effectively become another form of taxation.

\section{Not drowning but waving}

Despite these and other pitfalls, the great majority of foreign researchers have a positive overall opinion of living and working in Japan, citing excellent research infrastructure, generous and reliable funding and highly motivated students as reasons to move here. However, most stress that Japan takes patience and warn that the life may not suit everyone. For Laurent Safa, a French engineer with more than a dozen years' experience in the Japanese telecoms industry, clues to why some foreigners struggle to adapt came as he has watched his two children go through their education in local schools. In Japan, he notes, "They place a much greater emphasis on group harmony, and that permeates through society. No matter how long you are in Japan, because you were not raised here, you are always going to feel like an outsider in some way." Reffert, who had studied in various countries before taking up her current position, describes Japan as her most interesting so far but admits that "some people definitely struggle."

Others, however, evidently thrive and come to view Japan as much more than just a stepping stone to their next position. Like Maturana at the NUT, the IMSUT's Patil is also in it for the long haul. With her family settled and both her and her husband's careers progressing well, she acknowledges that Japan is her future. "But I need to learn Japanese," she says, "because this is now home."

Nature editorial staff have no responsibility for content. 


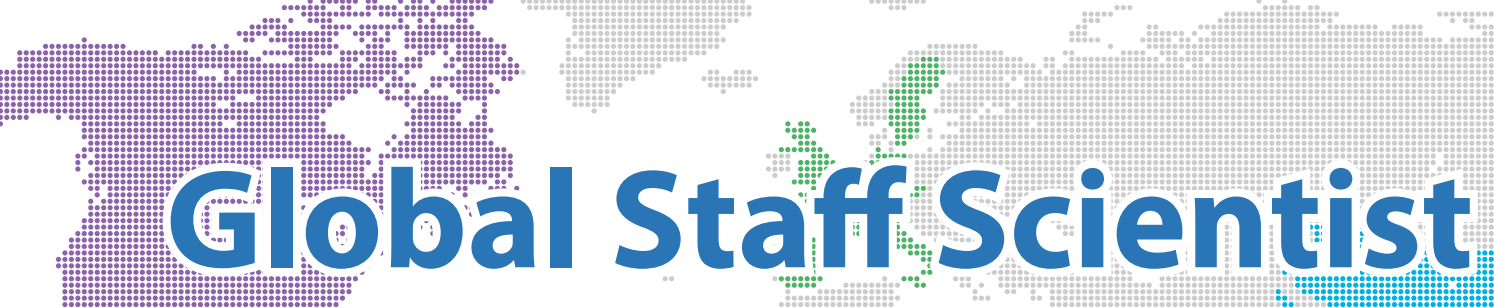

Position Available

Otsuka Pharmaceutical Co., Ltd invites applications for the position of scientist to lead the gilobal develöpment of new CNS drugs. The successful applicant will lead a team of passionate professionals who strive to advances șence, technology, and medicine by developing products designed to help people live better lives. The successful applicant will start employment as a permanent employee at Tokushima Prefecture in:Japan. However, he or she will be required to work at Otsuka facilities worldwide including USA, EU, Canada, China, and so on. The starting date is as soon as practicable in 2011.

\section{Qualifications and Experience:}

$\mathrm{PhD}$ degree with two to five years combined post-doctoral and industrial experience, preferably in the pharmaceutical industry or biotechnology sector.

- Life scientist with expertise in neuroscience, or a medicinal and organic chemist.

घ Disease area: Schizophrenia, Bipolar, Major depressive disorder, Alzheimer's disease, Parkinson's disease, and Epilepsy.

घ Should display the attributes of a true leader and innovator.

- Fluent English speaker in order to have excellent global communication.

- No Japanese language skill is required. Otsuka is committed to ensuring the successful applicant's smooth transition to life in Tokushima. This includes Japanese language classes.

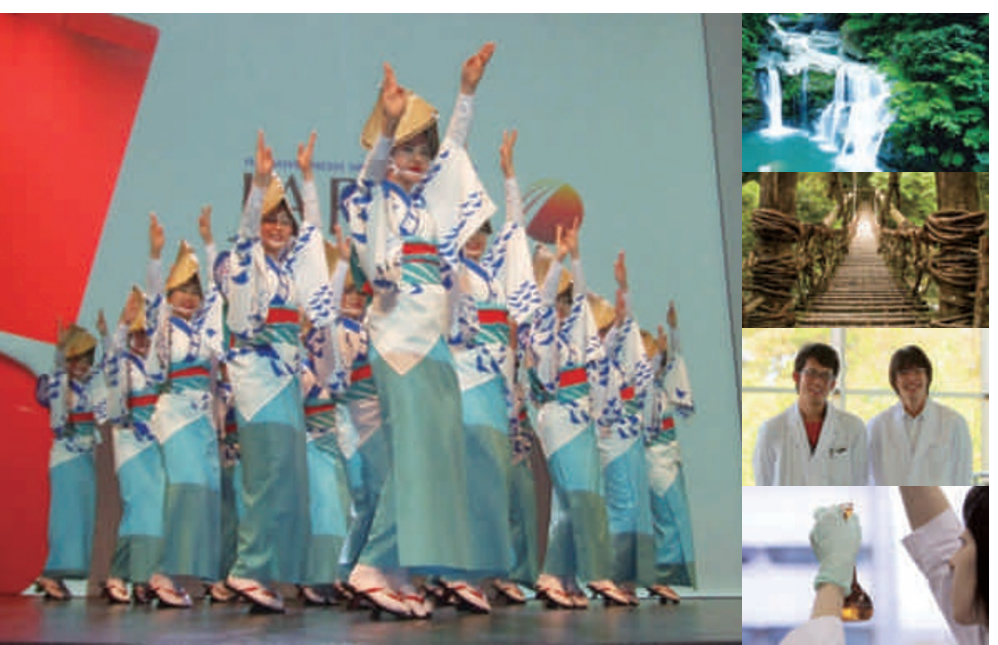

Applicants should include a curriculum vitae written in English with a recent photograph, a list of publications; and a statement explaining former research/ work experience. Please keep application material to no more than five pages. Applications should be sent to:

\section{Human resources department, Otsuka Pharmaceutical Co., Ltd. 463-10 Kagasuno, Kawauchi-cho Tokushima 771-0192, Japan}

Or Email: recruitRD@otsuka.jp (The entire application should be converted to PDF)

Review of applications will begin on December 16, 2010. However, the search for candidates will remain open until the position is filled.

For further information, please visit our Homepage: www.otsuka.co.jp/en/

Salary: Annual stipend will be from $\$ 70,000$, higher for experienced senior researchers.

Benefit Package: Housing allowance, health Insurance, commuting allowance, and corporate pension.

\section{Life in Tokushima:}

Tokushima Prefecture is located in the eastern part of Shikoku, and can be reached from Tokyo in one hour by airplane. Tokushima is blessed with natural beauty and a lively culture. Its citizens enjoy a comfortable laid back lifestyle close to two of Japan's major population centers Kobe and Osaka.

For further information, please visit:

www.awanavi.jp/english/

Awa Dance is a traditional art performed in Tokushima, especially in August. Otsuka's Awa Dance team (left) is indicative of Otsuka's company culture of community support and encouragement. The team annually joins regional and world festivals, bringing the appealing culture of Awa Dance to people worldwide.

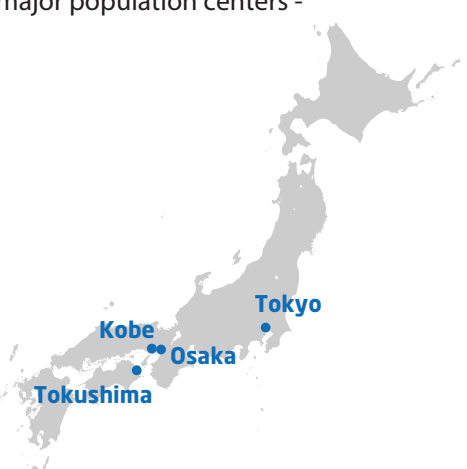

\section{- Otsuka Otsuka Pharmaceutical Co., Ltd.}


International

Balzan Foundation "Prize"
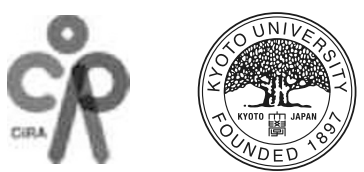

\section{5-year Individual Researcher Position -Yamanaka-Balzan Award-}

Center for iPS Cell Research and Application (CiRA), Kyoto University

Director: Shinya Yamanaka

CiRA invites applications for a 5-year individual researcher position, with research expenses. In September 2010, the International Balzan Prize Foundation gave an award to Prof. Yamanaka for his efforts to generate iPS cells from somatic cells. Based on this award, CiRA has established the "YamanakaBalzan Award" to support a young researcher who can contribute to research on the mechanisms of direct reprogramming and further application of iPS cell technology. The position allows the selected researcher to conduct iPS cell research for 5 years with research expenses of 100,000 Swiss francs/year. Faculty title will depend on her/his achievements and experience.

Please refer to our website for details:

http://www.cira.kyoto-u.ac.jp/e/employment.html

\section{Work Place CiRA, Kyoto University, Japan}

Qualifications Researcher with less than 10 years of research experience since obtaining Ph.D. (As of October 2010)

Job Conditions [Term] 5 years (from April 1, 2011) [Salary] In accordance with Kyoto University Regulations

[Research expense] 100,000 Swiss francs/year

* Other necessary human resources or equipment is provided by $\mathrm{CiRA}$, separately.

How to apply Applicants should mail CV, list of research achievements and some other required documents to the postal address listed below by January 13th. Please see our website for details and download the forms. (Applying by e-mail is not acceptable.)

Contact: Tetsuya Ishii

Head of the Research Management Office

Center for iPS cell Research and Application (CiRA),

Kyoto University

(53 Kawara-cho, Shogoin, Sakyo-ku, Kyoto, Japan 606-8507)

E-mail collaboration@cira.kyoto-u.ac.jp
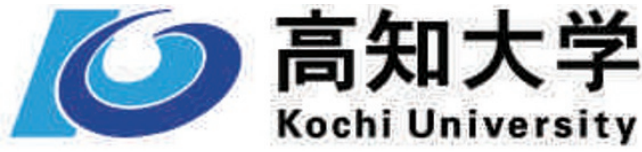

Tenure Track Positions (Chemical Biology and Synthetic Chemistry) Promotion Program for Young Scientists and COE for Innovation of Marine Science and Technology

The National University Corporation Kochi University Kochi, JAPAN

We have initiated the "Promotion Program for Young Scientists and COE for Innovation of Marine Science and Technology" supported by MEXT in Fiscal Year 2010. In order to implement this program, we offered internationally six tenure track positions (designated lecturers or designated assistant professors) to candidates who are able to take the lead in the fields of Marine Chemistry and Marine Bioscience. As for two research fields, the application deadline was on October 29 th. Since, candidates qualified for these two positions were not identified. We hereby extend the deadline and re-advertise the positions of these researches.

1. Number of Tenure Track Positions Available and Research Fields

Two tenure track teachers (designated lecturers or designated assistant professors) One position for each research field; (1) Chemical Biology (2) Synthetic Chemistry

2. Qualifications (Applicants should fulfill the following criteria :)

(1) hold a doctoral degree on natural science or have a good prospect of being awarded a doctoral degree by the end of March, 2011.

(2) possess skill, knowledge or experiences to carry out research on interdisciplinary areas of Marine Chemistry and Marine Bioscience.

(3) have a good enthusiasm and knowledge for the guidance and training of researchers, and display a positive attitude toward activities such as contributions to community and society, etc.

(4) have the ability at communicating in English.

3. Term of the Appointment

From the earliest possible time after March 1, 2011 to March 31, 2015

The candidates who successfully complete the five year term and are identified as qualified at the end of the fifth year will be tenured.

4. Duration of Registration and Selection Schedule

(1) Closing date for submission of application documents

5:00 pm, January 31, 2011 (JST) When we find candidates who are well qualified for each research fields, we will close the advertisement.

(2) First screening (review of documentation): Early February, 2011

(3) Second screening (interviews): Mid or late in February, 2011

5. Contact Information for Application Submissions and Inquiries

Special Research Projects Supporting Office, Evaluation and Support Organization for Young Researchers, Kochi University, E-mail: kk41@kochi-u.ac.jp

Please refer to our homepage (http://www.kochi-u.ac.jp/imt/english) for further information.

JP207067R

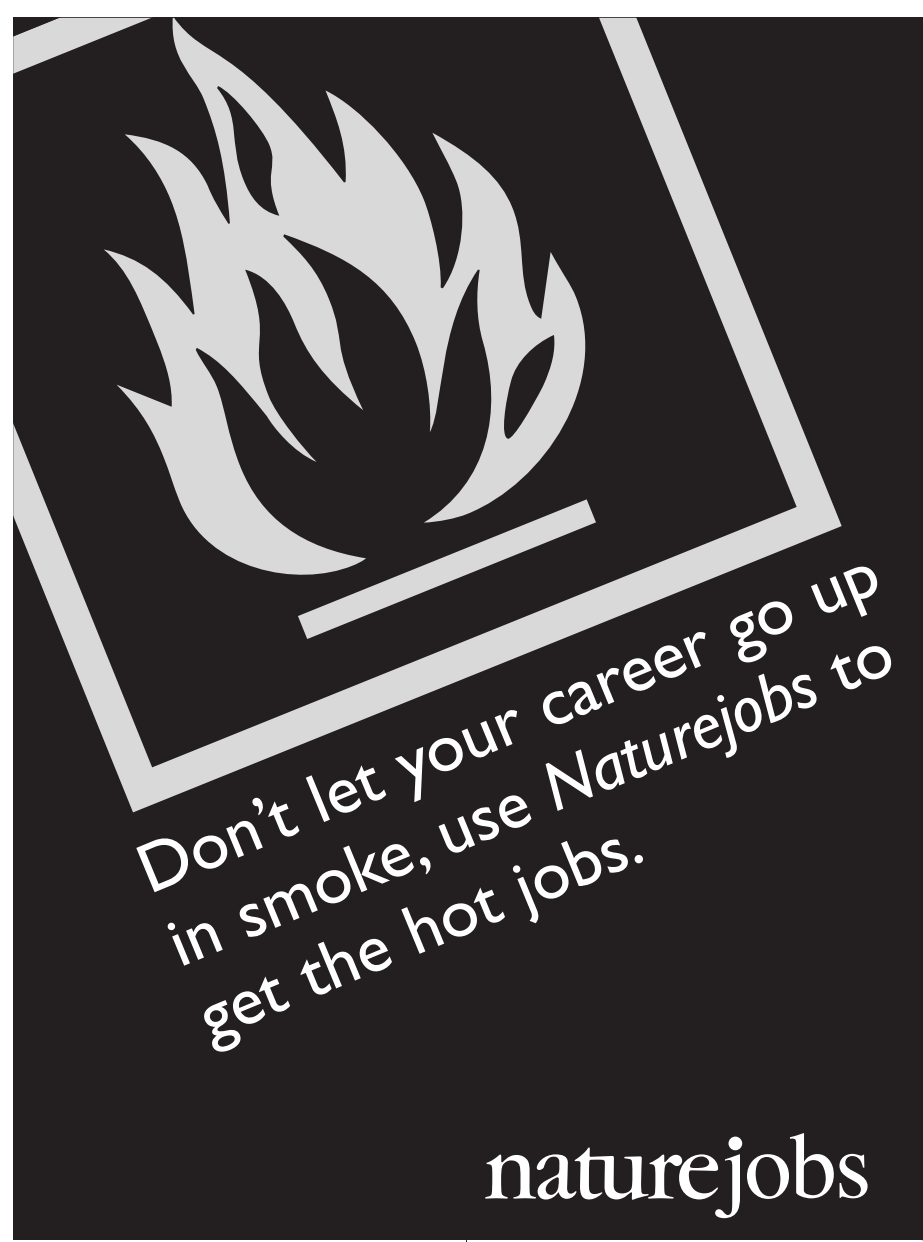

